or when escaping from a human enemy or from a dangerous animal, the thickness of the sole, its insensibility to pain, and its resistance to wear and tear must have often determined life or death. A man who became sore-footed after a long day's tramp, or one whose thin sole was easily cut or torn by stones or stumps, could never compete with his thicker soled companions, other things being equal; and it seems to me that it would be difficult to choose a single physical character whose variations would be more clearly subject to the law of selection.

With the greater portion of Prof. Lloyd Morgan's very interesting address I am in perfect accord, and it is because his remarks and suggestions are usually so acute and so well founded that I have thought it advisable to point out where I think that his objections have a less stable foundation.

Alfred R. Wallace.

\section{A Rare Phenomenon.}

THE rare phenomenon to which your two correspondents refer in their letters in your last issue (p. 494) was visible here at precisely the same time, and, viewed from Nottingham Forest, it presented a most interesting sight. It is curious that, as both the time and duration of the phenomenon coincide with its appearance here, its characteristics should be so dissimilar. It had more the appearance of a well-defined display of the aurora. Rays of light springing from the horizon penetrated high into the heavens, lasting about ro or 15 seconds, and then disappeared, others taking their places. Its centre appeared to me to be almost due north, and, from notes made at the time, the beams or luminous rays reached an angle of about $50^{\circ}$, stars being visible through them. There was no arc visible of the character described by your correspondents, but vertical changing ravs, several of which were distinctly orange-tinted.

Nottingham, September 26.

ARTIIUR Marshall.

Your columns record, from Ireland and Scotland, observations of the aurora to which I called attention last week. It was seen also in Warwickshire, the coruscations being so marked as to remind my informant of the search-light at the Naval Exhibition. Mr. E. B. Knobel informs me that, from 8 to Io p.m. on the IIth, during which time the appearance was visible, active magnetic disturbances were noticed at the Royal Observatory, Greenwich, illustrating the close connection which has been established between auroral and magnetic phenomena.

W. TUCKWELL.

IT may be of interest to your readers to know that the "rare phenomenon" mentioned (p. 494) was seen by me from Ryde, I.W., on Friday, the IIth. A streak of light (at first thought to be a ray proceeding from a search-light), was visible near the Pleiades, a! about 9.30, extending over an arc of about $45^{\circ}$, the width being probably about $I^{\circ}$. It gradually faded away, and at ro no trace of it was left. F. C. LEVANDER.

30 North Villas, Camden Square, N. IV., September 28.

\section{Instruments in Just Intonation.}

As you have raised once more the question of justly intoned instruments, may I offer the following remarks? It does not seem likely that any arrangement for the organ would be practically adopted unless it permits as much freedom of modulation and of execution as that of equal temperament. To permit perfectly free modulation, with practically perfect intervals, nothing short of the cycle of fifty-three will suffice. Now to construct a key-board with fifty-three notes to the octave which can be played upon with the facility of a twelve-note key-board seems impossible. But the problem may be approached differently: as it is only necessary to use twelve notes at a time, the key. bo:rd might remain as it is, and cnly a mechanical device would be required to make these twelve keys correspond to the right twelve out of fifty-three pipes; if the services of an assistant be allowed (as is often necessary on large organs) the mechanical difficulties could easily be overcome. For example, arrange a number of studs-say II 7, as suggested by Dr. Ellis-as a "duodenarium," and connected electrically to the fifty-three trackers; i.e. each tracker would be connected to two or three studs $-B^{3} b b, C^{4}$ bob, $A_{3}$ studs to tracker 46 for instance.
Opposite these studs would be another set of II 7 connected to the twelve keys, e.g. C, $\mathrm{B}_{2} \amalg, \mathrm{B}_{3}$ Between the two sets of studs would be a frame carrying twelve contact pieces; the frame would then be moved along guides by the assistant, so that the twelve keys were electrically connected to the right duodene of studs, and hence could be made to open the right group of pipes.

Thus the only alteration in printing required would be to mark the duodene on the music. All the extra complication would be thrown on the mechanical arrangements, and the organist would be left in the same position as now. It seems to me that any more complicated key-board would fail in a large organ, through overburdening the organist.

Firth College, Sheffield, September I4 RoBT. A. LEHFELdT.

\section{Unusual Frost Phenomenon.}

The following is extracted from a letter dated Dubbo Creek, near Tumut, New South Wales, July 26, 1891 :-

"I noticed the other day a strange effect caused by the late very hard frosts. It was a peculiar upheaval of the crust of the ground by a mass of innumerable threads of ice taking the form of spun glass or fine asbesto; fibre. There were five layers of this ice-fibre, the uppermost bearing the raised earth-crust. Every night's frost was shown by its distinctive layer of fibres.

"As perhaps you may never have seen this form of ground frost, I append a rough sketch of its very singular appearance.

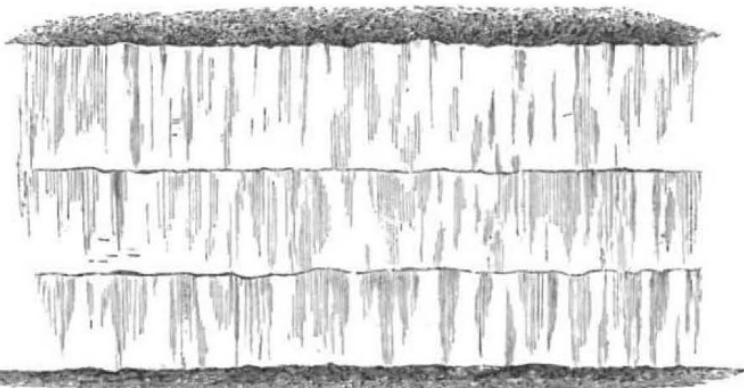

I have only shown three layers; there were five, but this may give you some idea of its appearance-quite a columnar basaltic appearance.

"Every morning here after a sharp frost, the whole of the ground, where not covered by grass or rubbish, is raised up thus. On the sides of the cuttings and banks of our claim, these ice-fibres may be seen projecting from the walls in bunches of snowy filaments, like spun glass. The sun, however, soon causes them to drop off, and they lie in heaps of some six inches in dep! h."

Richmond, Surrey.

A. H. White,

\section{The Destruction of Mosquitoes.}

ON two occasions, when proceeding northwards to Arctic Norway, I was much interested in observing the fact that the plague of mosquitoes, which is so intolerable there, especially prevails in latitudes beyond the northern range of the swallow.

This may possibly be a mere coincidence, but $I$ think it is not -an opinion strongly supported by another and very broad fact, viz. that in a given district in our own country the gnats become more abundant immediately after the departure of the swallows, martins, \&c. If this view is correct, the protection of these birds should be added to the devices named in your review of "Dragon-fies $v$. Mosquitoes." Such protection is very different from the indiscriminate sentimentalism about "small birds" which breaks out periodically at this season in the newspapers, and includes such feathered vermin as the thick-billed, seed-grubbing, pea-shelling, graminivorous sparrow among the objects of its tenderness.

The Grange, Neasden, N.W. 